\title{
How Komondor Dogs Reduce Sheep Losses to Coyotes
}

\author{
JOHN C. MCGREW AND CINDY S. BLAKESLEY
}

\begin{abstract}
Nine Komondor dogs were observed guarding lambs in two 65-ha enclosures for $\mathbf{2 1}$ days each. Each enclosure had a resident coyote chosen for sheep-killing ability. Komondorok guarded sheep by being near the flock and actively defending it when necessary. Guarding was most effective in the area where the dogs spent most of their time. Aggressive dogs were generally more successful protecting their sheep. The sheep learned to run to or stand with the dogs when attacked, and usually bedded with the dog. The coyotes learned to attack the flock when the dog was not present. Effectiveness of Komondor dogs can be enhanced by exploiting breed characteristics.
\end{abstract}

Livestock guardian dogs are common in the Old World (Coppinger and Coppinger 1978) but were virtually unknown in the United States before the mid-1970's. However, since the 1972 Presidential ban on the use of Compound 1080 and other toxicants, dogs have enjoyed increasing popularity as an environmentally acceptable means of reducing coyote (Canis latrans) predation. A majority of dog owners polled rated their dogs as good to excellent at reducing sheep losses to coyotes (Green and Woodruff 1980, Newbold 1980). Articles by stockmen (Gerber 1974, Adams 1978) agree that dogs reduce losses but offer little reliable evidence of how this is accomplished. Some authorities are skeptical about the use of guardian dogs (Wade 1978).

The U.S. Fish and Wildlife Service, Denver Wildlife Research Center, conducted a brief field evaluation of one popular guardian breed, the Hungarian Komondor, to collect empirical data on the effectiveness of dogs. Linhart et al. (1979) trained four adult Komondorok (plural form) to attack coyotes and stay with sheep in fenced pastures. Sheep kills by coyotes decreased significantly during and following the use of the dogs, suggesting that they were a deterrent to coyote predation. The Denver study was unable to determine how Komondorok reduced predation, although pheromones, barking, coyote neophobia, and coyote-dog encounters were suggested as possible explanations (Linhart et al. 1979:240).

In this report we present the results of a field trial of Komondorok guarding sheep under controlled conditions. We also offer recommendations for increasing the effectiveness of Komondor dogs as flock guardians. Our objectives in this study were to determine how the dogs protected sheep from a coyote, particularly the behavioral interactions involved, and to answer some of the questions raised by Linhart et al. (1979).

During research the authors were Ph.D. and M.S. candidates, respectively, in the Department of Zoology and Entomology, Colorado State University, Fort Collins, Colo. 80523

This research was funded by USDA/ ARS Cooperative Agreement No. 58-9AHZ8-334 with Colorado State University.

Authors would like to acknowledge T. Harris's assistance in collecting data. They are also grateful to J. Green, R. Woodruff, and T. Kellum of the U.S. Sheep

Experiment Station for their assistance and cooperation, and thank the U.S. Sheep Experiment Station and the USDA/ARS for providing sheep, coyotes, living accommodations, and research facilities at the Station during this study.

Finally, they wish to thank J. Green, P. Lehner, and E. Pexton for their helpful comments on an early draft of this manuscript.

Manuscript received February 23, 1981.

\section{Methods}

We conducted field trials with 9 Komondor dogs in two 65-ha (160-acre) enclosures at the U.S. Sheep Experiment Station (USDA/ARS), Dubois, Ida. The dogs are subjects of a 3-year study of the efficacy of using Komondor dogs to protect sheep from coyote predation. At the time of the study, they were 26 months old.

The USSES is located on the Upper Snake River Plain, a province characterized by extensive lava fields (Hunt 1974). The terrain is level to slightly rolling, but broken by irregular rocky mounds and folds formed by lava flows. The vegetation is primarily sagebrush-bunchgrass (Blaisdell 1958), with the principal plants in the enclosures being sagebrush (Artemisia spp.), antelope bitterbrush (Purshia tridentata), rabbitbrush (Chrysothamnus spp.), and wheatgrasses (Agropyron spp.). Pricklypear cactus (Opuntia spp.) were also common in the enclosures.

The enclosures in which the trials were conducted are part of a full section ( $260 \mathrm{ha}$ ) set aside for predator research at the USSES. The enclosure fences are constructed of $2.5 \mathrm{~cm} \times 5.0 \mathrm{~cm}$ wire mesh, $2.4 \mathrm{~m}$ high with a $31-\mathrm{cm}$ wire-mesh overhand at the top of the fence and a buried $62-\mathrm{cm}$ wide apron at the bottom (Fig. 1). The research area is located approximately $3.2 \mathrm{~km}$ from the station headquarters and is readily accessible by road. Dirt roads parallel all of the fences and connect major features within each 65 -ha enclosure. The northwest (NW) and southeast (SE) enclosures were used simultaneously in the present study.

We conducted trials from 15 May to 21 September 1980. On 14 May we released the first 25 lambs (white face $\times$ Suffolk crossbred, average weight: $25 \mathrm{~kg}$ ) into each enclosure. These lambs, and all others used during the summer, had no previous experience with dogs or coyotes. Water was available ad lib in tanks filled 2 or 3 times per week. The sheep were able to find sufficient natural forage until about mid-July, after which we supplemented their diet with alfalfa pellets fed from a large feeder located near the

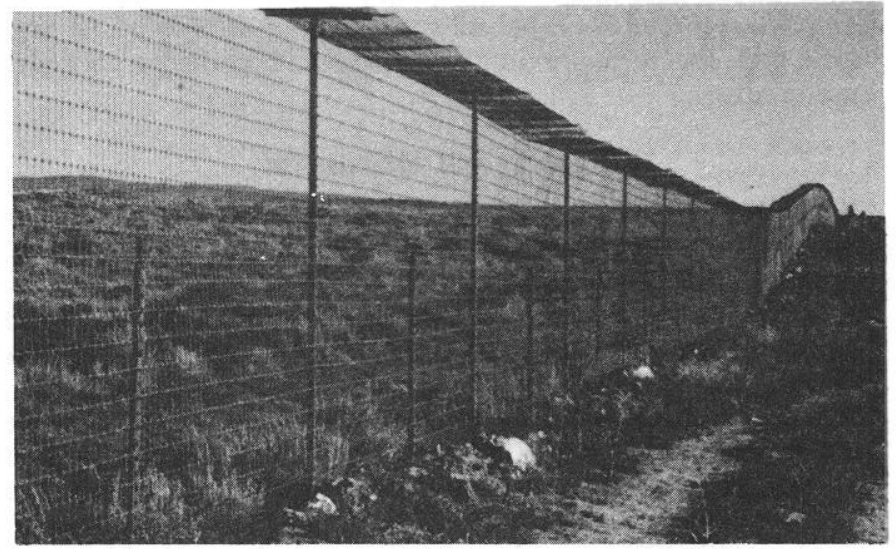

Fig. 1. Detail of enclosure fence of the coyote research facility, U.S. Sheep Experiment Station (USDA/ARS), look:ng east on the north side of SE enclosure. Note $31-\mathrm{cm}$ overhang at top, mesh construction, and rocks covering 62-cm aprong at bottom. 
Table 1. Schedule of trial phases and observation periods. Observation periods alternated between the 2 dogs under study during each trial. Observations were conducted on days marked " $x$."

\begin{tabular}{|c|c|c|c|c|c|c|c|c|c|c|c|c|c|c|c|c|c|c|c|c|c|}
\hline \multirow[b]{3}{*}{ Trial day } & \multirow{3}{*}{\multicolumn{2}{|c|}{12}} & \multirow{2}{*}{\multicolumn{4}{|c|}{ Introductory Phase }} & \multirow{2}{*}{\multicolumn{2}{|c|}{ Period I }} & \multirow[b]{3}{*}{9} & \multirow{2}{*}{\multicolumn{9}{|c|}{$\begin{array}{l}\text { Performance Phase } \\
\text { Period II }\end{array}$}} & \multirow{2}{*}{\multicolumn{3}{|c|}{ Period III }} \\
\hline & & & & & & & & & & & & & & & & & & & & & \\
\hline & & & 3 & 4 & 5 & 6 & 7 & 8 & & 10 & II & 12 & 13 & 14 & 15 & 16 & 17 & 18 & 19 & 20 & 21 \\
\hline $\mathrm{AM}$ & 1 & $\mathrm{X}$ & $\mathrm{x}$ & $\mathbf{x}$ & & & 2 & $\mathrm{X}$ & $\mathrm{X}$ & $\mathrm{x}$ & & & & $\mathrm{X}$ & $x$ & $\mathrm{x}$ & & & & $\mathrm{x}$ & $x$ \\
\hline PM & $\mathbf{x}$ & $\mathbf{x}$ & $\mathrm{x}$ & & & & $\mathrm{x}$ & $\mathrm{X}$ & $\mathrm{x}$ & & & & $\mathrm{X}$ & $\mathrm{x}$ & $\mathrm{x}$ & & & & $\mathrm{X}$ & $\mathrm{x}$ & 3 \\
\hline
\end{tabular}

1 Dog introduced

${ }^{2}$ Dog and sheep released from 0.8 -ha pasture

${ }^{3}$ Dog removed

water tanks. Sheep killed during the summer we re removed daily and replaced periodically so that flocks usually numbered 25 at the beginning of each trial.

We released a single adult male coyote into each of two enclosures at the beginning of the trials and left it undisturbed for the remainder of the summer. Both coyotes were 3 years old and weighed about $11 \mathrm{~kg}$ when released. They were selected from the USSES kennels on the basis of their ability to kill sheep in pen trials. Both were fitted with radio transmitter collars before release into the enclosures.

Each trial consisted of two phases (Table 1). During the Int roductory Phase we placed the dog under observation with the lambs in a 0.8-ha (2-acre) pen in one corner of the 65-ha enclosure. We provided food and water for the sheep and dog in the pen. The introduction allowed a brief time for the dog to become accustomed to the vegetation and terrain features, and for the dog and sheep to adjust to each other. On Day 7 we released the sheep and dog from the pen and allowed them access to the entire 65-ha enclosure. The trial then continued for an additional 14 days (the Performance Phase).

Onc of us visited both enclosures every day to insure sufficient food and water were available and to remove sheep carcasses. Aside from these daily visits, we did not interfere with the dog in any way once its trial began. With few exceptions, the dogs were unaware of our presence in the enclosures during observations. A small booth mounted on the bed of a military surplus lift-bed truck served as an observation tower. The truck could be moved, and usually it was parked approximately in the middle of the active enclosure. Visibility from the booth, which could be raised to height of about $5 \mathrm{~m}$, was generally good, although some parts of both enclosures were obscured by vegetation or terrain features.

We observed the dogs, sheep, and coyotes on 11 of the 21 days of the trial (Table 1). Morning sessions began at first light and lasted until the coyote and sheep became inactive, usually by 0930 . Evening sessions lasted from 1700 to 1800 until dark. We occasionally made unscheduled observations on other days of the trial. All observations were made by the authors or an experienced technician. We recorded location, movements, and activity of the dog, flock and coyote continuously in field notebooks or on audio casette tapes.

\section{Results and Discussion}

The dogs patrolled, barked (especially at night), and scentmarked around the sheep as suggested by Linhart et al. (1979). None of these behaviors appeared to repel the coyotes permanently. Rather, the dogs protected sheep by being near the flock and actively defending it. In 79 of the 153 coyote-sheep interactions which we observed, the sheep either stayed with or ran to the dog, and in 75 of the 79 the dogs stood between the sheep and the coyote or chased the coyote away. The dog ran to the sheep and repelled the coyote in 5 additional instances. Sheep were never attacked while with a dog. The need for active defense explains why tethered dogs were sometimes unable to prevent predation in the Linhart et al. study.

The dogs all formed an attachment to one area of the enclosure, usually the area around the gate. Linhart et al. (1979) noted a similar pattern. Their dogs roamed over about $20 \%$ of one 130 -ha pasture, and movements of their dogs, like ours, were related to the location of food, water, and other dogs. Our dogs spent an average of $74 \%$ (range 30 to $98 \%$ ) of their time within $90 \mathrm{~m}$ of the main gate. The overall result of this site fidelity was that the dogs guarded most effectively when the sheep were within the dogs' preferred areas.

The dogs' attraction to sheep offset their site fidelity to some extent. The sheep left the dogs' areas several times each day for food and water. Some of the dogs were indifferent to sheep and rarely followed when they left the gate. Others followed only briefly or for short distances. Only one dog (Cyborg) regularly accompanied sheep for periods of time as long as an hour.

Being with the sheep was only one component of guarding behavior. The dog also had to repel the coyote when necessary, sometimes repeatedly. We observed a total of 141 interactions between dogs and coyotes ranging in duration from 2 seconds to 25 minutes. Eighty-four of the interactions involved the dog interrupting a coyote attack on sheep. Aggressiveness varied from dog to dog. One male showed little reaction to the coyote other than approach and raised-leg urination (RLU). One of the females was chased almost $700 \mathrm{~m}$ in her only recorded encounter with the coyote. She stayed away from the gate for 2 days afterward. Buff, Cyborg ( $\delta \delta$ ), and Calahan (q) unhesitatingly chased coyotes on their first exposure and every chance thereafter. Chases were rarely longer than $50 \mathrm{~m}$. This lack of predisposition for chasing appears to be a Komondor breed characteristic.

Aggressiveness sometimes varied from day to day for the same dog. For example, late in the evening of Day 18 of her trial, Babe actively defended her sheep from the coyote for over 2 hours. The coyote approached the flock at least 10 times during this period, and Babe repelled it each time. Yet, the next morning the coyote managed to separate the sheep from Babe and to drive them away from the gate. She made no attempt to follow or chase the coyote, perhaps because the sheep quickly left her preferred area.

Finally, aggressiveness increased over the course of the trial for some dogs. Cecily ran from the coyote on her first encounter (Day 8). On Day 10 she chased the coyote away from the flock, but then turned and ran when it challenged her. Finally, on Day 15 she chased the coyote away several times without retreating.

An important factor not noted by Linhart et al. (1979) is the behavior of the sheep. In our study the sheep appeared to learn to avoid the coyote by going to or staying with the dog. In over half of the coyote attacks, the flock stood with or ran to the dog. As the study progressed the sheep established their bedding ground at the gate and spent an increasing amount of time there. The sheep also increased the dogs' effectiveness by detecting the coyote. Komondorok have good olfactory and visual acuity (pers. obs.), but they rarely detected the coyote before the shecp did.

Despite their selection for similar sheep-killing ability, there was a distinct difference in the predatory behavior toward sheep shown by the two coyotes, the NW coyote being noticeably less persistent and aggressive. The sheep responded by adopting two different defensive strategies. The flock in the NW enclosure stood and faced the coyote on 34 of 53 encounters, whereas the SE flock relied on the proximity of the Komondor dogs for defense from the more 
Table 2. Results of the 9 Komondor sheep-guarding trials.

\begin{tabular}{|c|c|c|c|c|c|c|}
\hline \multirow[b]{3}{*}{ Dog } & & \multirow{3}{*}{$\begin{array}{c}\text { Total observation time } \\
\text { (hours) }\end{array}$} & \multicolumn{4}{|c|}{ Total kills } \\
\hline & & & \multirow[b]{2}{*}{ Introductory phase } & \multicolumn{3}{|c|}{ Performance phase } \\
\hline & Sex & & & Period 1 & II & III \\
\hline \multicolumn{7}{|l|}{ SE Enclosure } \\
\hline Babe & $\mathbf{F}$ & $38^{\mathrm{a}}$ & 4 & 2 & 2 & \\
\hline Buff & M & 59 & 1 & 2 & 2 & \\
\hline Cecily & $F$ & 75 & 5 & 3 & 1 & 1 \\
\hline Calahan & $\mathbf{F}$ & 70 & & 2 & 1 & \\
\hline Cyborg & $\mathbf{M}$ & 64 & & 1 & & \\
\hline \multicolumn{7}{|l|}{ NW Enclosure } \\
\hline Bo & $\mathbf{M}$ & 62 & & & & 1 \\
\hline Bess & $\mathrm{F}$ & 81 & & 1 & 1 & \\
\hline Breese & $F$ & $6 !$ & 1 & 2 & 2 & \\
\hline Blue & $\mathrm{F}$ & 73 & & 1 & 1 & \\
\hline
\end{tabular}

${ }^{a}$ Time reduced by bad weather

aggressive coyote. They stood and faced the coyote on only 11 of 93 encounters.

In contrast, certain sheep behaviors increased their vulnerability. The flock in the NW enclosu re was never strongly cohesive, and several kills resulted from fragmentation of the flock (Blakesley and and McGrew, unpub. data). The sheep in both enclosures of ten became active before dawn, especially during warm weather, and moved away from the dogs to graze or go to water. This behavior exposed them to predation from the coyotes, which were most active just before dawn, and often resulted in a sheep being killed less than $200 \mathrm{~m}$ from the gate with no interfence from the dog.

Both coyotes spent considerable time within $100 \mathrm{~m}$ of the flock (at least $26 \%$ of the total active time for the SE coyote), and both coyotes regularly challenged the dogs. If a dog ran from either coyote, the coyote would chase. Some dogs chased the coyote, and it ran just far enough and fast enough to avoid the dog. Number and duration of coyote-dog interactions differed from dog to dog. Buff, who was somewhat clumsy and slow, was challenged more often and longer than was Cyborg, who nearly caught the coyote on two occasions.

Sheep losses during our study were higher than anticipated: of 89 sheep exposed to the coyotes over the summer, 37 were killed (Table 2). However, our objective in this experiment was not to determine if Komondork could guard sheep. We accepted the experiences of stockmen and the results of Linhart et al. (1979) as proof of the breed's potential. Rather, we hoped to observe how the dogs protected sheep, the development of guarding behavior, and the mechanisms involved. This information could then be used to improve rearing and training methods and to identify situations most suited to the temperament of the breed.

Our procedure had the effect of challenging the dogs' guarding abilities by placing them at a disadvantage in relation to the coyote. We trucked them 3 or 4 at a time over $1000 \mathrm{~km}$ from Fort Collins to the USSES and housed them in strange kennels. In addition, we made no effort to familiarize them with the enclosure prior to Day 1 of their trials, when we simply put them with an unfamiliar band of sheep in a small pen. The pen fences limited the range of the dogs and sheep, but did not exclude the coyotes, who dug holes under the fences and killed a total of 11 sheep during the Introductory Phases of four different trials (Table 2). The 65-ha enclosures used after Day 7 were much larger and rougher than the 4- to 6-ha grassy pastures in Colorado where the dogs had previously worked.

The dogs also had to contend with coyotes chosen for aggressiveness and sheep-killing ability. We did not feed the coyotes, and, although they killed small birds and mammals on occasion, sheep were their principal prey. Furthermore, the enclosure fence limited the coyotes to 65 ha and a maximum distance of $1100 \mathrm{~m}$ from the flock. This level of predation pressure would be unlikely in a normal production situation.

Wade's argument (1978) that the adaptability of coyotes would limit the effectiveness of guard dogs was supported only in part. The coyotes appeared to assess the dogs' abilities and to kill sheep when the dogs were not with the flocks. However, the dogs also adapted to the coyote and changed their behavior, even during the short trial period. Cecily showed the greatest improvement, and her increased aggressiveness resulted in reduced predation from Period I to Period III of her Performance Phase (Fig. 2).

In addition, the behavior of the sheep changed, generally improving the dogs' effectiveness in guarding. The dynamic nature of the dog-sheep relationship (and the possibility of enhancing the relationship through training) suggests that it may be an effective counter to flexibility in coyote behavior.

The dogs in this study were relatively young and continued to show improvement after 3 weeks (Table 2). In our study and in Linhart et al. (1979), even the best dogs did not totally eliminate coyote predation. Guard dogs are not a perfect method and should

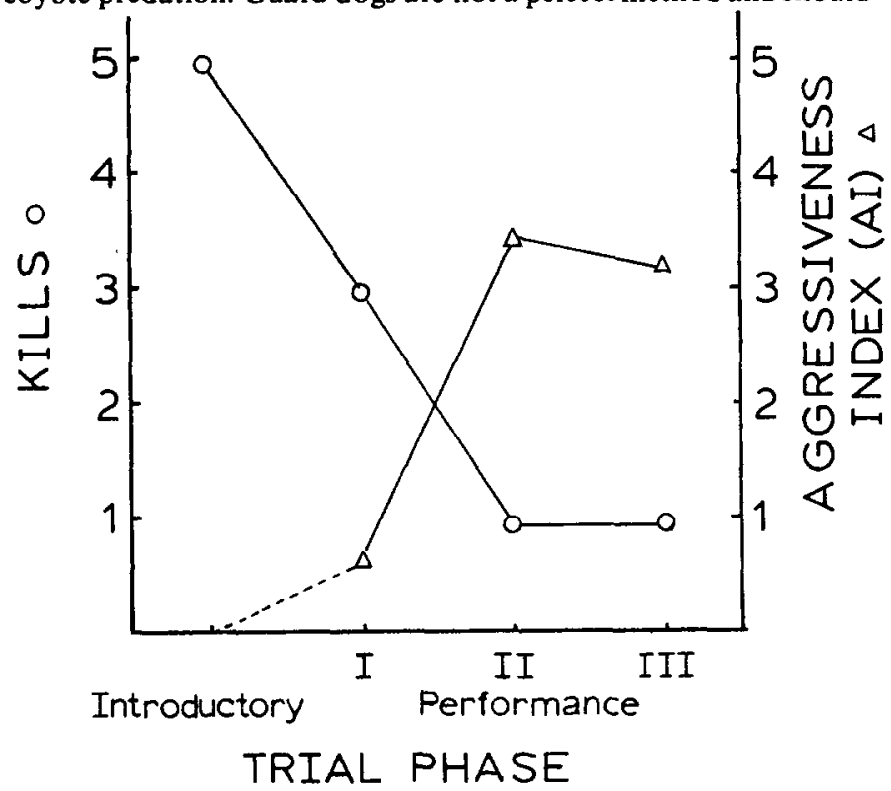

Fig. 2. Coyote predation declined as Cecily's aggressiveness increased during the course of her trial. The Aggressiveness Index is calculated by the formula

$$
A I=\frac{\Sigma\left(I_{i} \times D_{i}\right)}{\Sigma D_{i}}
$$

where $1=$ intensity of dog-coyote interactions on a 7-point scale and $D=$ duration of the interactions ( $N=23$ interactions). No interactions between Cecily and the coyote were noted during the Introductory Phase. 
be considered one of a variety of control methods which can be combined with sound husbandry practices to reduce sheep losses (Lehner 1976, Anonymous 1980).

Wade's suggestion that unattended Komondorok might be a hazard to animal or human life was unsupported. Linhart et al. (1979) reported that one of their dogs attacked and killed sheep. Some livestock producers have also complained of their dogs chasing sheep. However, none of our dogs were observed harassing sheep at any time during the summer, perhaps due to their early social experience with sheep. As a result, even naive sheep quickly accepted the dogs' presence near the flock. Komondorok have a very low tendency to chase, and it seems unlikely that they would attack wildlife. It is true that Komondorok are generally aggressive and protective dogs, but early social experience with a variety of people seems to alleviate excessively aggressive behavior towards humans (pers. obs.). Ourdogs are either friendly to most people, or are shy of all humans except us.

\section{Recommendations for Using a Komondor}

The Komondor was developed by the early Hungarians as a flock guardian. It is a large breed with a heavy coat and predisposition for protecting property. No training as such is required to bring about guarding behavior, and probably no amount of training can make a flock guardian of a dog which lacks the intelligence, independence, and aggressiveness for the job. This does not mean, however, that Komondorok guard "instinctively" or that an individual dog does not require training to be useful. Rather it means that a dog can be an effective livestock guardian if it possesses the basic breed characteristics and if it is properly trained. Training and human influence are required in at least three areas: early socialization, obedience, and flock management.'

Training and rearing procedure should capitalize on two basic behaviors of the breed:

1. Komondorok are very conscrvative in nature. They adjust to the initial situation and react to change or novelty. This conservative nature is reflected in the traits we see in the breed: intelligence, stubbornness, aggressiveness, shyness, and strong habit formation.

2. Adult Komondorok have a low inclination to chase. Sheep accept them because they do not act like other dogs. Because they can stay close to the flock, Komondorok become attached to sheep (strong habit formation).

Early exposure to sheep and humans, if properly supervised, will likely eliminate many behavior problems in adult dogs. Exposure to sheep does not necessarily create an attachment, but rather acquaints the dog with the smell, sound, and behavior of sheep. Thus, it is not necessary to expose a 6- to 13-week-old puppy in order to achieve the desired result. In fact, puppies that are frightencd or injured at this age can retain a lifelong aversion to sheep. On the other hand, dogs which are not exposed to sheep until maturity may become overly attached to humans.

We feel that a 6- to 10-month-old dog is ideal. It is less fearful and fragile than a puppy, yet young enough to transfer its affection to sheep. Also, its basic "personality" and physical structure are already evident. We recommend the following procedures in training a new Komondor of any age.

1. Place the dog with sheep immediately upon arrival at the farm or ranch and leave it there. The area should be large enough for the dog to move freely, but secure enough to prevent escape. It should include a sheltered place where the dog can retire from the sheep.

2. Choose the sheep to complement the dog's personality. We have found that yearling ram lambs do well with large, aggressive dogs, while bummer lambs are more suitable for small or shy dogs.

3. Supervise early contacts with sheep very carefully. Do not leave the dog unattended for long periods of time until it is clearly

i $A$ brief guide to training a Komond or as a flock guardian is available from the senior author. adjusted to the situation. Concentrate on building confidence by praising and rewarding desirable behavior.

4. Ignore (not punish) undesirable behavior unless it threatens the sheep. Chasing especially must be curbed since it can carry over into adulthood if learned as a puppy. Chewing ears and pulling wool are other traits which cannot be tolerated.

5. Give the dog at least basic obedience training. For the safety of sheep and humans the owner must have control over the dog. Obedience training also provides an opportunity for development of an affectionate dog-human bond. Work with the dog on a regular basis in the pasture with the sheep so that training becomes associated with the pleasure of the owner's company and with sheep.

6. As the dog matures and becomes accustomed to being with sheep, move it to situations which provide progressively more freedoms and opportunities for independent action. Continue to monitor it carefully, encouraging good behavior and showing displeasure at bad behavior.

The breed's conservative nature can be exploited by leaving the dog with the flock throughout the production cycle. A working Komondor is not a pet. It should not be driven around in a truck, nor kept at the house or sheep camp. The tendency to guard an area can be enhanced by regularly walking the dog around pasture fences, feeding it only in the pasture, discouraging it from crossing fences, and firmly returning it to the pasture if it leaves. The dog's movements in the pasture can be influenced by the location of its food and water, the placement of shelters, and the activity of the sheep. Moving the sheep to another pasture, especially one unfamiliar to the dog, can upset the dog, and the owner may need to spend extra time familiarizing it with the new area. Komondorok eventually become accustomed to routine moves with the flock and can guard pastures of 200 ha or larger, but because of their strong site fidelity, they may be less adaptable to open range operations than are other guardian breeds.

Finally, the rancher should consider sheep behavior in response to the dog. Bands should be split or changed as infrequently as practical. Sheep should be left with the dog permanently, even during shipping and in feedlots. Many owners even allow their dogs access to lambing operations. Since Komondorok may have 6 to 10 or more years of service with a flock, it is possible within a few years for virtually every sheep to have known the dog since birth.

\section{Literature Cited}

Adams, H. 1978. Maggie-The Komondor. A diary. Middle Atlantic States Komondor Club, Inc., Princton, N.J. 11 p. (mimeo.)

Anonymous. 1980. Experts offer cautions on use of livestock guard dogs. The Nat. Wool Grower 70(12):30-31.

Blaisell, J.P. 1958. Seasonal development and yield of native plants of the Upper Snake River Plains and their relation to certain climatic factors. USDA Tech. Bull. No. 1190:1-68.

Coppinger, R., and L. Coppinger. 1978. Livestock guarding dogs for U.S. agriculture. Livestock Dog Project, Chestnut Hill Road-RFD, Montague, Me. 22 p.

Gerber, P. 1974. Legalized poison-Komondorok. The Nat. Wool Grower 64(9):22.

Green, J.S., and R.A. Woodruff. 1980. Is predator control going to the dogs? Rangelands 2:187-189.

Hunt, C.B. 1974. Natural Regions of the United States and Canada. W.H. Freeman, San Francisco. 725 p.

Lehner, P.N. 1976. Coyote behavior: implications for management. Wildl. Soc. Bull. 4:120-126.

Linhart, S.B., R.T. Sterner, T.C. Carrigan, and D.R. Henne. 1979. Komondor guard dogs reduce sheep losses to coyotes: a preliminary evaluation. J. Range Manage. 32:238-241.

Newbold, V. 1980. Non-lethal methods-boon for some, bust for others. The Nat. Wool Grower 70:14-16.

Wade, D.A. 1978. Coyote damage: a survey of its nature and scope, control measures and their application, p. 347-368 In: M. Bekoff (Ed.), Coyotes: Biology, Bchavior, and Management. Academic Press, New York. 384 p. 